\title{
Mo-Doped CuO Nanomaterial for Photocatalytic Degradation of Water Pollutants under Visible Light
}

\author{
Mudassar Maraj ${ }^{1,2}$, Ahmad Raza ${ }^{2}$, Xinjie Wang ${ }^{1}$, Jie Chen ${ }^{1}$, Khalid Nadeem Riaz ${ }^{3, *}$ and Wenhong Sun ${ }^{1,4, *}$ \\ 1 Research Center for Optoelectronic Materials and Devices, School of Physical Science and Technology, \\ Guangxi University, Nanning 530004, China; mudassar@mail.ustc.edu.cn (M.M.); \\ wangxinjie2020@163.com (X.W.); a709161389@163.com (J.C.) \\ 2 Department of Physics, University of Gujrat, Gujrat 50700, Pakistan; 18151710-030@uog.edu.pk \\ 3 Department of Physics, University of Okara, Okara 56300, Pakistan \\ 4 Guangxi Key Laboratory of Processing for Non-Ferrous Metallic and Featured Materials, School of Resources, \\ Environment and Materials, Guangxi University, Nanning 530004, China \\ * Correspondence: khalid.nadeem@uog.edu.pk (K.N.R.); 20180001@gxu.edu.cn (W.S.)
}

check for updates

Citation: Maraj, M.; Raza, A.; Wang, X.; Chen, J.; Riaz, K.N.; Sun, W. Mo-Doped CuO Nanomaterial for Photocatalytic Degradation of Water Pollutants under Visible Light. Catalysts 2021, 11, 1198.

https://doi.org/10.3390/catal11101198

Academic Editor: Luigi Rizzo

Received: 15 September 2021

Accepted: 29 September 2021

Published: 30 September 2021

Publisher's Note: MDPI stays neutral with regard to jurisdictional claims in published maps and institutional affiliations.

Copyright: (c) 2021 by the authors. Licensee MDPI, Basel, Switzerland. This article is an open access article distributed under the terms and conditions of the Creative Commons Attribution (CC BY) license (https:// creativecommons.org/licenses/by/ $4.0 /)$.

\begin{abstract}
Recently, metal oxide-based nano-photocatalysts have gained much attention in waste water remediation due to their outstanding properties. In this report, a novel Mo-doped $\mathrm{CuO}$ nanomaterial was successfully prepared and utilized for the degradation of methylene blue water pollutant. The molybdenum content was varied from 1-5 wt.\% to obtain the desired modified $\mathrm{CuO}$ based nanomaterials. The crystalline structures of as prepared materials were investigated by XRD diffraction technique, which explored the successful fabrication of monoclinic structure based $\mathrm{CuO}$ nanomaterials. For morphological study, SEM and HRTEM techniques were probed, which had also proved the successful preparation of nanoparticles-based material. SAED is used to check the crystallinity of the sample. The EDX and XPS analysis were performed to evaluate the elemental composition of Mo-doped $\mathrm{CuO}$ nanomaterials. The optical characteristics were explored via UV-vis and PL techniques. These studies have showed that the energy bandgap of $\mathrm{CuO}$ was decreased from $1.55 \mathrm{eV}$ to $1.25 \mathrm{eV}$ due to Mo doping. The photocatalytic efficiency of Mo-doped $\mathrm{CuO}$ nanomaterials was evaluated by degrading methylene blue (MB) under visible light-irradiation. Among different Mo-doped $\mathrm{CuO}$ based nanomaterials, the 4 wt.\% Mo-doped $\mathrm{CuO}$ sample have shown highest degradation activity against MB dye. These results verified that the optimized material can be used for photocatalytic applications, especially for the purification of waste water.
\end{abstract}

Keywords: nanostructured; Mo-CuO; sol-gel; photocatalysis; methylene blue

\section{Introduction}

Fresh water is crucial for the existence of life. About 70 percent of the Earth is covered by water, but a very small portion of this (2.5\%) percent is available for different purposes. Uncontrolled population growth in the world has proliferated the industrial revolution, which has caused the pollution of land and water bodies, especially by industrial wastes, which are highly toxic and hardly degradable [1]. Most of the textile industries use large amount of water for the process of dying and cleaning. During the manufacturing of textile items, the 50 percent of dyes are mixed in wastewater. The dissemination of this contaminated wastewater in the environment is a major source of pollution. Residential wastewater includes poisonous species released from non-fabricating action including: deadwood, contagions, dangerous microorganisms, germ-free crops and wastage of cleaners, etc. The appearance of this untreated surplus of water is a substantial cause of water pollution [2]. The researchers have identified in their earlier studies that several management agencies have used different schemes for the recycling of discarded water, which approaches physically, biologically and chemically in nature [3]. The choice of scheme used depends on the source of the wastewater, either from industries and houses or some pharmaceutical 
products containing effluents, and thus the nature of pollutants in water and the related treatment techniques could differ from each other [4].

Among the different treatment approaches, the photocatalysis is the best technique for water purification. It is a method in which light energy is absorbed for the production of electron/hole pairs, which then starts redox reactions. These reactions happen at the same time on the surface of the photocatalyst material [5]. In recent years, photocatalysis has been developed as a versatile technique in many applications, including self-sterilizing, self-cleaning of glasses, water splitting, antifouling coatings, oxidation of organic contaminations, decomposition of crude oil and polyaromatic hydrocarbons, etc. [6]. The photocatalysis process is categorized into two categories, which are homogenous and heterogeneous photocatalysis, depending upon the phase state of the components. The homogeneous photocatalysis is disadvantageous as it progresses in low $\mathrm{pH}$ values, whereas for the precipitation and removal of ions from the systems, the high $\mathrm{pH}$ values are required [7]. On the other hand, in heterogeneous photocatalysis, a wide range of reactions occur, such as oxidation, exclusion of pollutants, isotopic exchange, detoxification and hydrogen removal, etc. [8,9].

In photocatalysis, many metal oxides like: $\mathrm{TiO}_{2}, \mathrm{ZnO}, \mathrm{MoS}_{2}$ and $\mathrm{CuO}$ etc. were used in waste water treatment [10-12]. Among these, $\mathrm{CuO}$ has distinctive features, such as low cost, non-toxic and highly stable nature under light irradiation, thus it has been used frequently in photocatalysis [13]. The $\mathrm{CuO}$ is a transition metal oxide having monoclinic structure. Copper $(\mathrm{Cu})$ possesses different oxidation states, such as: $\mathrm{Cu}^{1+}, \mathrm{Cu}^{2+}$, and $\mathrm{Cu}^{3+}$, which make it equally promising for both, holes and electrons doping [14]. Nowadays, $\mathrm{CuO}$ is being used as photocatalyst, antioxidant, drug delivery agent, and imaging mediator in the field of biomedicine [15]. Furthermore, in industrial fields, $\mathrm{CuO}$ is extensively used as a p-type semiconductor in photocatalysis, batteries, solar cells, gas sensors, and field emitters [16-18].

Previously, different researchers have worked to improve the photodegradation activity of $\mathrm{CuO}$ by doping it with different elements. For example, Shaban et al. have investigated the influence of $\mathrm{Fe}$ doping on $\mathrm{CuO}$ and found higher activity due to Fe doping [19]. Nuengruethai et al. prepared $\mathrm{Ce}$-doped $\mathrm{CuO}$ nanostructures and evaluated their photocatalytic activity against methylene blue (MB) [20]. Similarly, Devi et al. have optimized the photodegradation activity of $\mathrm{CuO}$ by doping it with $\mathrm{Tb}$. They have used a combustion method to fabricate these monoclinic $\mathrm{Tb}$-doped $\mathrm{CuO}$ nanoparticles. The enhanced surface area has played an important role to improve the degradation activity against different dyes [21].

In this study, we have prepared Mo-doped $\mathrm{CuO}$ nanomaterials using a sol-gel method by varying the content value from $1-5 \mathrm{wt} . \%$. The prepared photocatalytic material showed enhanced optical and photocatalytic properties due to the Mo doping.

\section{Results and Discussion}

\subsection{XRD Spectroscopy}

XRD spectroscopy was employed to examine the crystalline nature of the prepared nanomaterials. From the XRD patterns shown in Figure 1, it is clear that $\mathrm{CuO}$ nanoparticles showed a highly crystalline nature. Sharp peaks were obtained at $36^{\circ}$ and $38^{\circ}$ correspond to the diffraction from the (111) and (002) planes. Further peaks were attained at $33^{\circ}, 49^{\circ}, 53^{\circ}$, $58^{\circ}, 62^{\circ}, 66^{\circ}, 68^{\circ}, 72^{\circ}$ and $75^{\circ}$ were consistent to diffraction for planes $110,020,202,-113$, $-311,220,311$, and 222, separately, according to the JCPDS data card No. 80-1916 [22]. It can be observed that, on $\mathrm{Mo}$ in $\mathrm{CuO}$, the peaks intensities were gradually decreased with an increasing content of Mo. In order to confirm this change, the crystalite size of the samples were calculated using the Debye Sherrer formula, as given in Equation (1).

$$
D=\frac{0.94 \lambda}{\beta \cos \theta}
$$



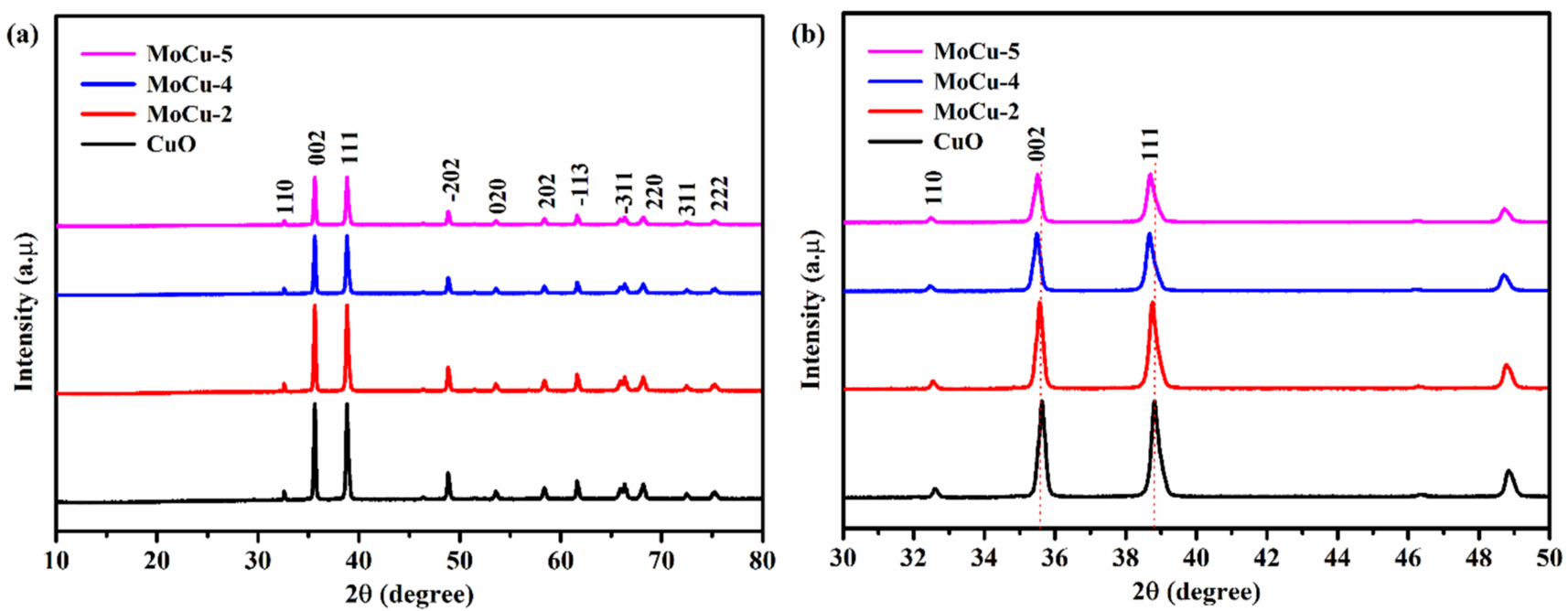

Figure 1. XRD pattern of pure $\mathrm{CuO}, \mathrm{MoCu}-2, \mathrm{MoCu}-4$, and $\mathrm{MoCu}-5$ samples. (a) $2 \theta$ (degree) from 10-80; (b) 20 (degree) from 30-50.

Here, $\lambda=1.54056 \AA$ is the X-ray's wavelength, " $\beta$ " is the full width at half maximum, and " $\theta$ " is the Bragg's angle of the diffraction peak in radians [23]. Using the above equation, the average crystallite sizes for the pure $\mathrm{CuO}$ and $\mathrm{Mo}$-doped $\mathrm{CuO}$ samples were found to be 17.9 and $12.9 \mathrm{~nm}$, respectively. This clearly shows that the crystallite size of $\mathrm{CuO}$ was decreased due to Mo doping, which could be attributed to the difference between the ionic radii of $\mathrm{Mo}$ and $\mathrm{Cu}$, which are $0.068 \mathrm{~nm}$ and $0.073 \mathrm{~nm}$, respectively.

\subsection{SEM and EDX Analysis}

The SEM was utilized to analyze the morphological properties and size estimation of the prepared nanostructures. The SEM images of $\mathrm{CuO}$ and $\mathrm{MoCu}-4$ are shown in Figure 2a,b, respectively. It can be seen from Figure 2a shows a material with randomly distributed nanoparticles on its surface, and some spaces for the smooth diffusion of ions. Figure $2 b$, is showing the SEM image of the MoCu- 4 sample. It can be observed that, after Mo doping, the material was converted into uniformly distributed nanosized particles. The average particle sizes of the $\mathrm{CuO}$ and $\mathrm{MoCu}-4$ samples are in the range of $65-75 \mathrm{~nm}$ and $30-40 \mathrm{~nm}$, respectively. This development of nanoparticles has improved the surface properties, active surface area, and a large number of active sites for the attachment and degradation of toxic-dyes molecules.

The elemental composition of the prepared samples was determined through EDX analysis. EDX plots of $\mathrm{CuO}$ and $\mathrm{MoCu}-4$ are revealed in Figure $2 \mathrm{c}, \mathrm{d}$. One can observe only peaks related to $\mathrm{Cu}$ and $\mathrm{O}$ in Figure 2c; thus, expressing the elemental purity of pristine $\mathrm{CuO}$. On the other hand, signals related to $\mathrm{Cu}, \mathrm{O}$, and $\mathrm{Mo}$ are appeared in the EDX plot of $\mathrm{MoCu}-4$, and are shown in Figure 2d, thus showing the successful doping of Mo in the $\mathrm{CuO}$ crystalline lattice. The weight percentages of $\mathrm{Cu}, \mathrm{O}$, and $\mathrm{Mo}$ in the $\mathrm{MoCu}-4$ sample were $38.12,57.04$, and 4.84 , respectively. These values are approximately in agreement with their used weight percentages during the synthesis process.

\subsection{HRTEM and SAED Studies}

For further confirmation of the prepared MoCu-4 sample, and to support the SEM results, HRTEM images were also obtained and are shown in Figure 3a,b. 
(a)

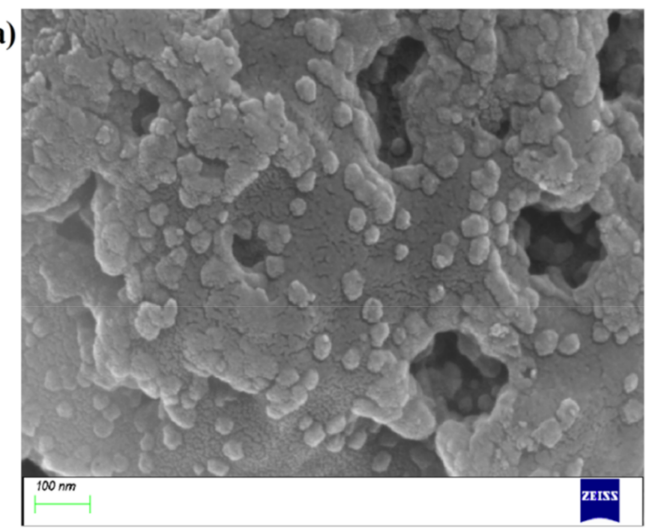

(c)

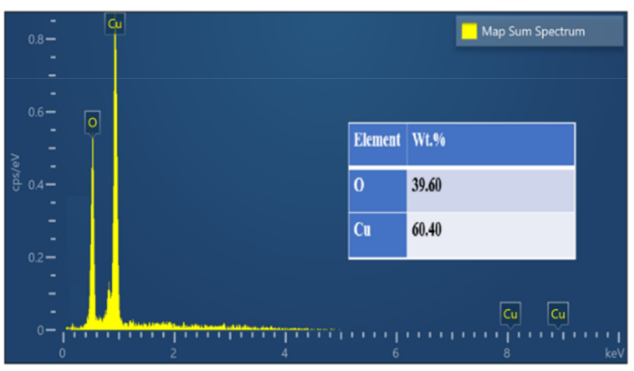

(b)

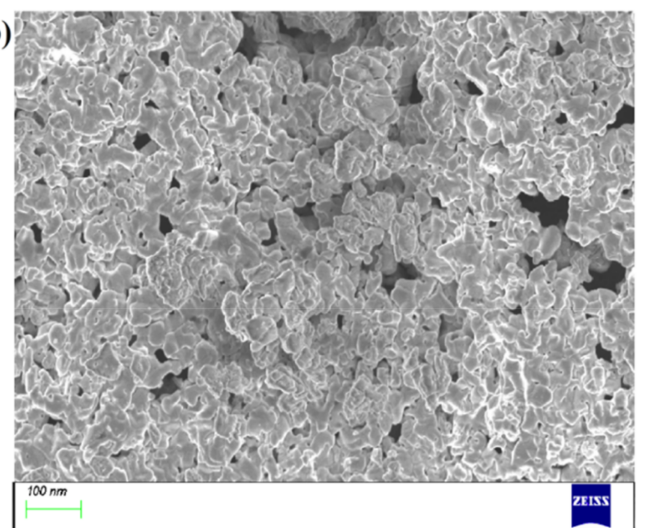

(d)

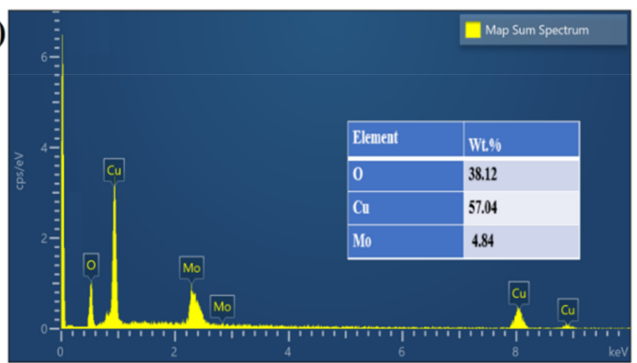

Figure 2. SEM images of (a) pure $\mathrm{CuO}(\mathbf{b}) \mathrm{MoCu}-4$ samples, EDX of (c) pure $\mathrm{CuO}$ and (d) $\mathrm{MoCu}-4$ sample.

(a)

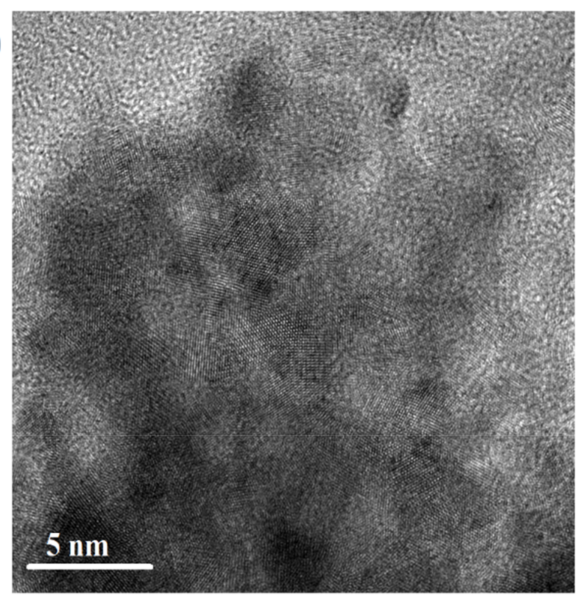

(b)

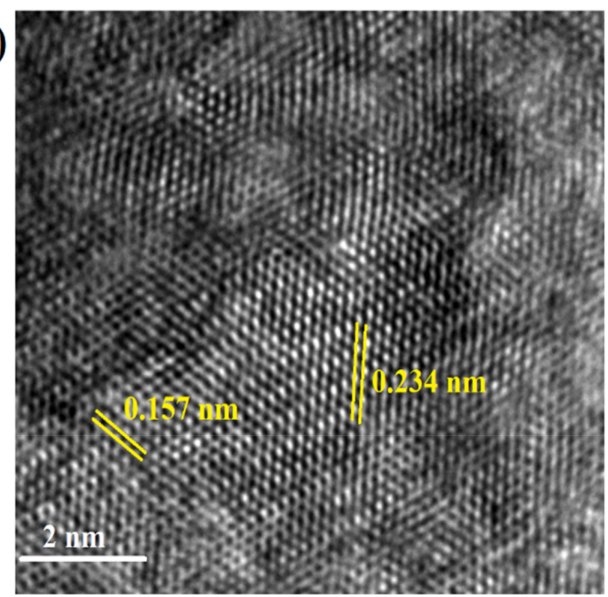

(c)

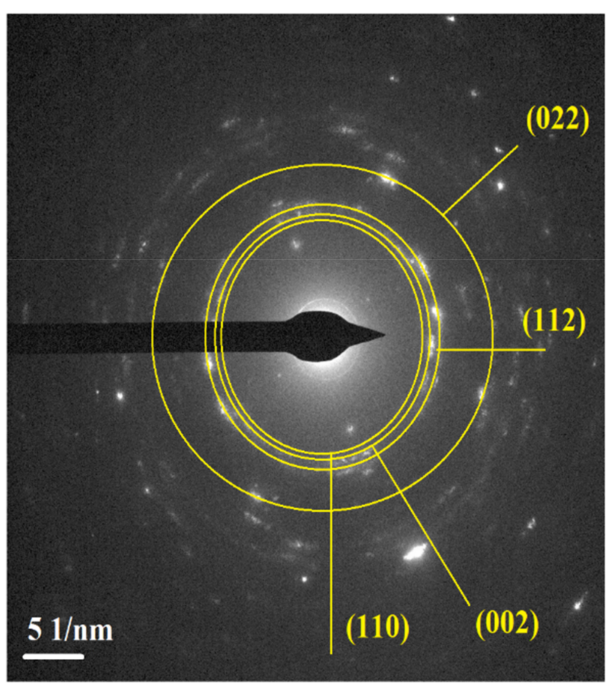

Figure 3. (a) HR-TEM image of MoCu-4, (b) HRTEM image of MoCu-4 and (c) SAED pattern of MoCu-4 sample. 
The micrograph shown in Figure 3b, exhibited the inter planar spacing of $0.234 \mathrm{~nm}$ and $0.157 \mathrm{~nm}$, corresponding to the (1 111$)$ and (202) crystalline planes of the monoclinic structure of $\mathrm{CuO}$. Furthermore, the SAED (Selected Area Electron Diffraction) pattern, which was obtained for the MoCu-4 sample, is shown in Figure 3c. From this, it is clear that this sample is polycrystalline in nature.

\subsection{XPS Analysis}

In Figure $4 a-d$, the XPS of MoCu-4 sample are shown, which signify the existence of the constituent elements, which are copper $(\mathrm{Cu})$, molybdenum $(\mathrm{Mo})$, and oxygen $(\mathrm{O})$, along with the carbon (C) shown as a reference in Figure 4a. In Figure $4 \mathrm{~b}$, the peaks shown at $933.4 \mathrm{eV}$ and $952.6 \mathrm{eV}$ are related to $\mathrm{Cu} 2 \mathrm{p}_{3 / 2}$ and $\mathrm{Cu} 2 \mathrm{p}_{1 / 2}$, which are the features of the $\mathrm{Cu}^{2+}$ ions [24]. Furthermore, the presence of $\mathrm{CuO}$ is also confirmed due to the appearance of peaks with binding energies of $942.11 \mathrm{eV}$ and $962 \mathrm{eV}$ [25]. The Figure 4c shows the two peaks at binding energies of $231.49 \mathrm{eV}$ and $234.79 \mathrm{eV}$, which can be indexed to the ${\mathrm{Mo} 3 \mathrm{~d}_{3 / 2}}_{2}$

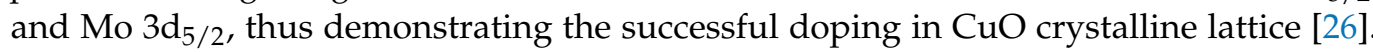
The Figure $4 \mathrm{~d}$ demonstrate the high-resolution XPS spectrum of $\mathrm{O} 1 \mathrm{~s}$ with one peak at $530.52 \mathrm{eV}$ [27].
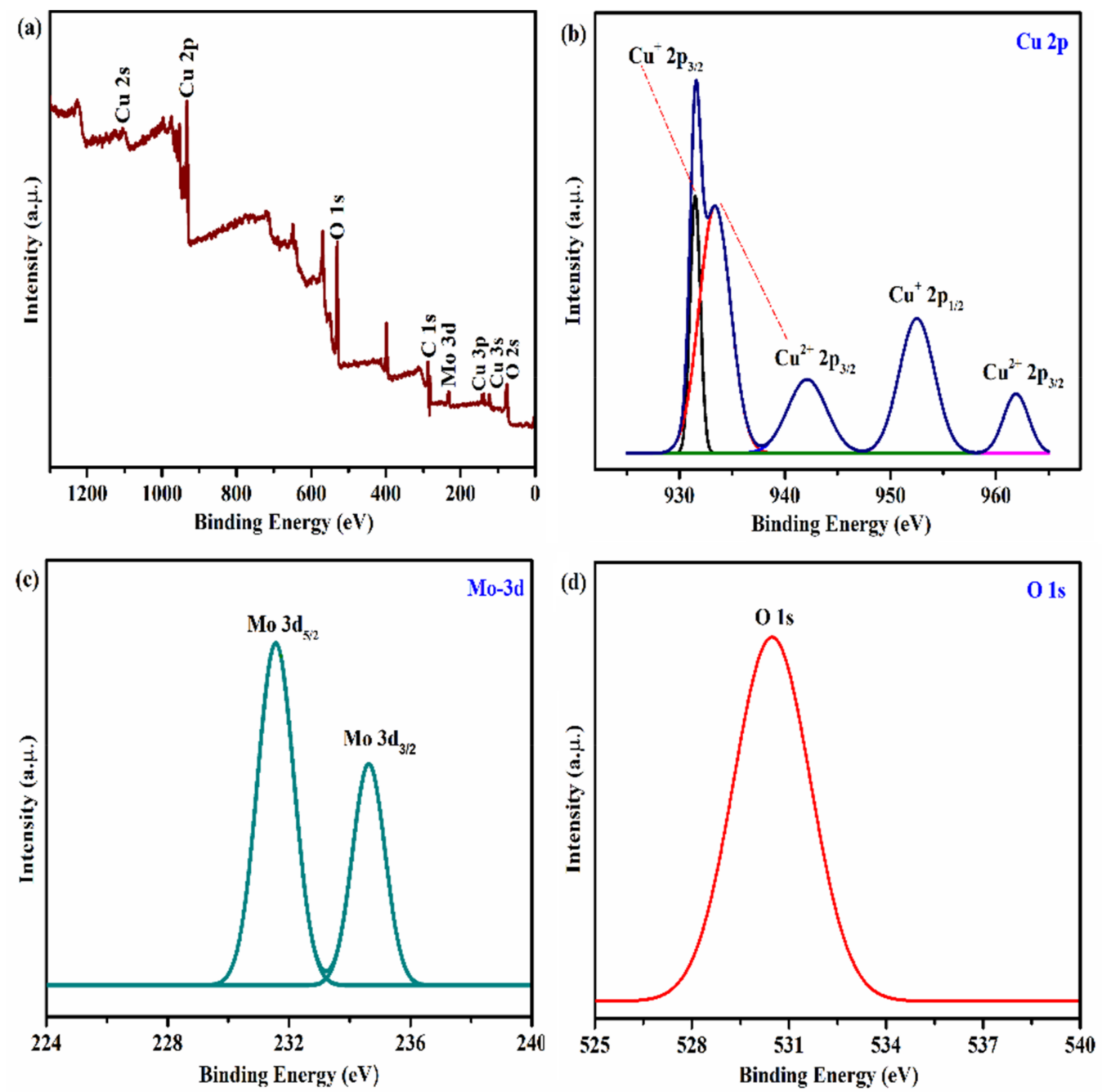

Figure 4. (a) XPS survey spectrum for MoCu-4, high resolution XPS spectra for (b) Cu 2p, (c) Mo-3d and (d) $\mathrm{O} 1 \mathrm{~s}$. 


\subsection{UV-Visible Spectroscopy}

For an efficient photocatalyst material, the narrower-optical bandgap is very essential to exhibit the highest photodegradation activity under the irradiation of visible light. To investigate the optical properties of $\mathrm{CuO}$ and $\mathrm{Mo}$-doped $\mathrm{CuO}$, the absorption spectra were obtained within the wavelength range of $750 \mathrm{~nm}$ to $1100 \mathrm{~nm}$ and are shown in Figure $5 \mathrm{a}$. The optical band gap values of these samples were found from the Tauc relation, which is given in Equation (2) [28].

$$
(a h v)^{2}=A\left(h v-E_{g}\right)
$$
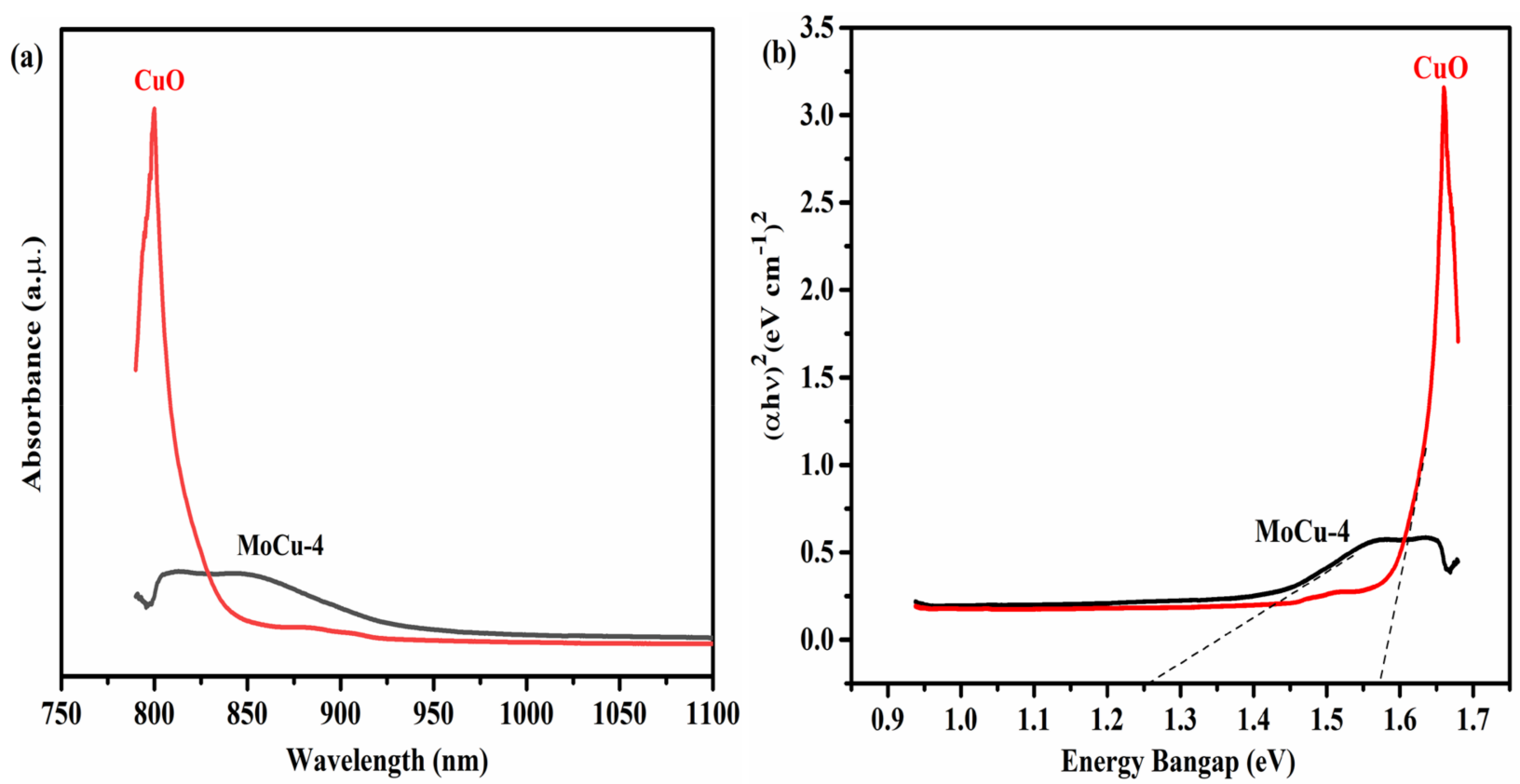

Figure 5. (a) UV-vis absorbance of pure $\mathrm{CuO}$ and $\mathrm{MoCu}-4$ samples and (b) Tauc plot of pure $\mathrm{CuO}$ and $\mathrm{MoCu}-4$ samples.

Here, " $E_{g}$ " stands for optical bandgap energy, " $v$ " is the frequency, " $h$ " is Planck's constant, and " $A$ " is a constant that relies on transition probability [29]. The estimated bandgap values for pure $\mathrm{CuO}$ was $1.55 \mathrm{eV}$ and for the $\mathrm{MoCu}-4$ sample is $1.25 \mathrm{eV}$ (shown in Figure $5 b$ ). This clearly shows a decrease in the band gap energy of $\mathrm{CuO}$ due to Mo doping. By decreasing the band gap, the catalyst absorb more light and electrons jump easily from the valance band to the conduction band. Electron and hole pairs form, which are required in dye degradation process.

\subsection{Photoluminence Spectroscopy}

PL emission spectra shows the proficient separation of electron/hole pairs and their recombination rate $[30,31]$. Figure 6 , show the emission spectra corresponding to pure $\mathrm{CuO}, \mathrm{MoCu}-1, \mathrm{MoCu}-2, \mathrm{MoCu}-3, \mathrm{MoCu}-4$, and $\mathrm{MoCu}-5$ samples.

The spectrum for pure $\mathrm{CuO}$ has shown the highest peak intensity. While the $\mathrm{MoCu}-1$, $\mathrm{MoCu}-2, \mathrm{MoCu}-3$, and $\mathrm{MoCu}-4$ samples has shown a gradual decrease in peaks heights, exhibiting well separation of electron hole pairs and the availability of band levels for the migration of electrons easily. However, the MoCu- 5 sample showed a higher PL emission intensity, which confirmes that $4 \mathrm{wt} . \%$ is an optimum level for Mo doping in $\mathrm{CuO}$. 


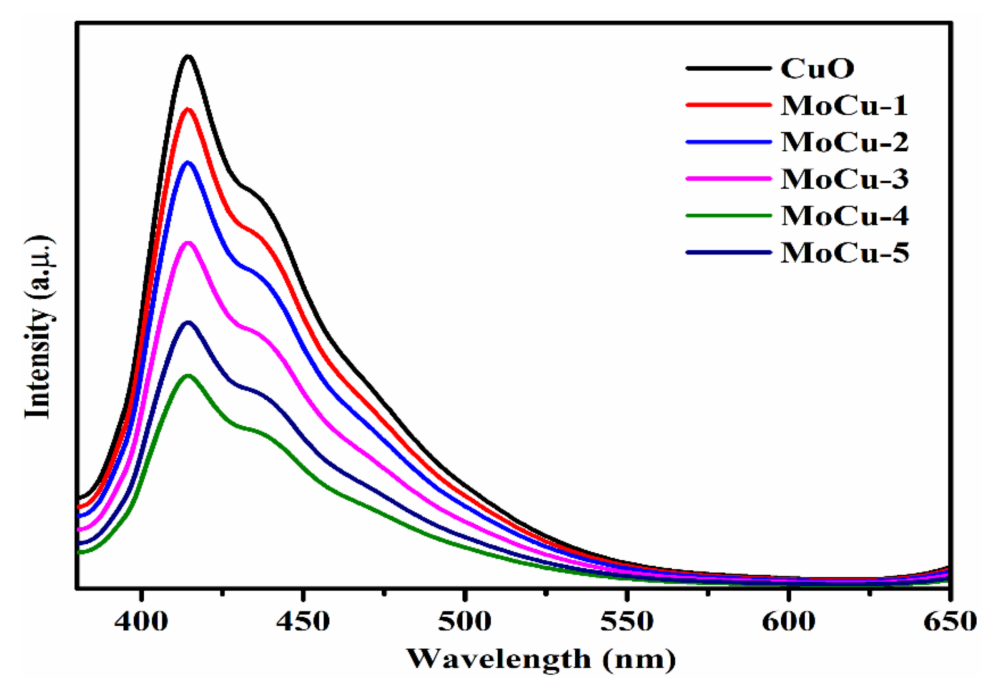

Figure 6. PL spectra for pure $\mathrm{CuO}, \mathrm{MoCu}-1, \mathrm{MoCu}-2, \mathrm{MoCu}-3, \mathrm{MoCu}-4$, and $\mathrm{MoCu}-5$ samples.

\subsection{Photocatalytic Activity}

The photocatalytic activity of pure $\mathrm{CuO}$ and $\mathrm{Mo}$-doped $\mathrm{CuO}$ samples was investigated by approximating the degradation of MB dye under visible light irradiation, $\lambda \geq 420 \mathrm{~nm}$, as shown in Figure $7 \mathrm{a}-\mathrm{c}$.
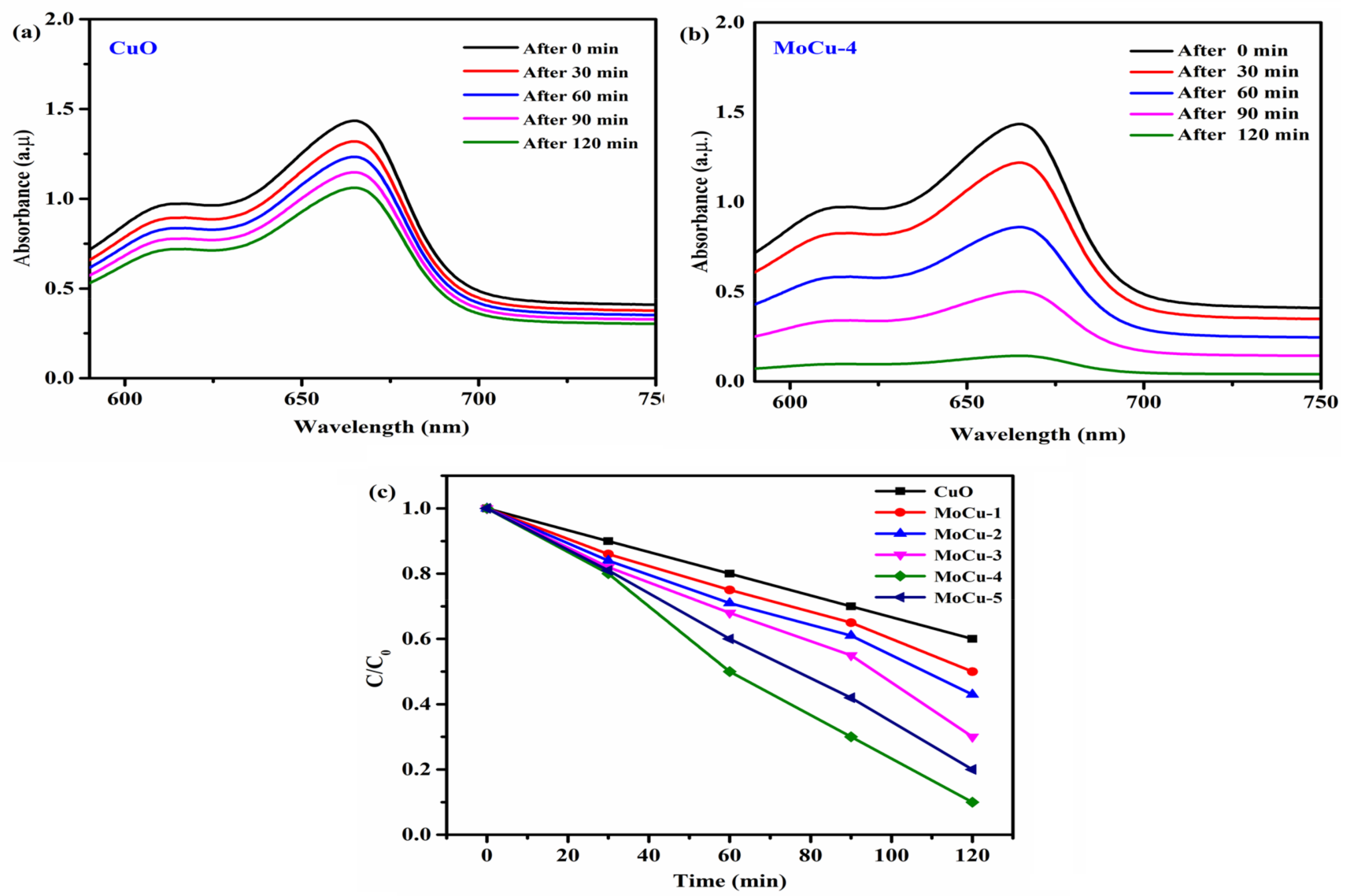

Figure 7. Photocatalytic activity absorption spectrum of (a) pure $\mathrm{CuO}$, (b) $\mathrm{MoCu}-4$ sample, and (c) photodegradation activity of pure $\mathrm{CuO}, \mathrm{MoCu}-1, \mathrm{MoCu}-2, \mathrm{MoCu}-3, \mathrm{MoCu}-4$, and $\mathrm{MoCu}-5$ samples.

The obtained absorption spectra in the degradation of methylene blue using $\mathrm{CuO}$ and MoCu-4 samples are shown in Figure 7a,b. Surprisingly, the absorbance of MB was 
noticeably reduced after $120 \mathrm{~min}$ for the sample $\mathrm{MoCu}-4$ (Figure $7 \mathrm{~b}$ ) in comparison to pure $\mathrm{CuO}$ (Figure 7c). Moreover, the Figure 7c, shows the comparison of the photocatalytic performance of different photocatalysts under visible light irradiation. The pure $\mathrm{CuO}$ nanomaterial exhibited very low performance under visible light irradiation. After doping $\mathrm{CuO}$ with molybdenum, the photocatalytic activity of the materials was significantly enhanced. The $\mathrm{MoCu}-4$ sample has shown the best performance, which demonstrated a $90 \%$ decrease of $\mathrm{MB}$ after $120 \mathrm{~min}$ of irradiation. The $4 \mathrm{wt} . \%$ Mo doped $\mathrm{CuO}$ has demonstrated a higher photocatalytic activity than the pure $\mathrm{CuO}$ and all the other doped materials. Furthermore, the MoCu-5 sample showed a lower performance than the $\mathrm{MoCu}-4$ photocatalyst, as confirmed by PL spectroscopy in Figure 6, thus low activity of the said sample.

\section{Experiment}

\subsection{Materials and Method}

A simple sol-gel method was used to prepare the Mo-doped $\mathrm{CuO}$ nanoparticles. During the synthesis, ammonium molybdate $\left(\left(\mathrm{NH}_{4}\right)_{6} \mathrm{Mo}_{7} \mathrm{O}_{24}\right)$ and coper nitrate $\left(\mathrm{Cu}\left(\mathrm{NO}_{3}\right)_{2}\right)$ were used as sources of molybdenum and copper, which were purchased from SigmaAldrich. Citric acid $\left(\mathrm{C}_{6} \mathrm{H}_{8} \mathrm{O}_{7}\right)$ was used for chelation. All these reagents were used as received without further purification. Stoichiometric amounts of ammonium molybdate, copper nitrate, and citric acid were dissolved in distilled water $\left(\mathrm{H}_{2} \mathrm{O}\right)$ for the formation of a homogeneous solution. The molar ratio among the nitrates and citric acid was 1:1 and the prepared solution was kept on stirring at $60^{\circ} \mathrm{C}$ until the formation of a gel was occurred. This gel was dried at the same temperature and then grinded by mortar to obtain a powdered form of the material. This powder was further calcined at $550{ }^{\circ} \mathrm{C}$ in a box type heating furnace for $2 \mathrm{~h}$. After cooling to the room temperature, the obtained powdered was further grinded by mortar to obtain fine nanoparticles. All concentrations were prepared by adopting the same synthesis method, and the 1-5 wt.\% Mo-doped $\mathrm{CuO}$ samples were labeled as $\mathrm{MoCu}-1, \mathrm{MoCu}-2, \mathrm{MoCu}-3, \mathrm{MoCu}-4$, and $\mathrm{MoCu}-5$. Moreover, the pristine $\mathrm{CuO}$ was obtained in the absence of a molybdenum source.

\subsection{Characterization}

The size of crystallite of the samples and the structural properties were investigated via XRD diffraction technique. The $\mathrm{Cu}-\mathrm{K} \alpha$ radiation with a wavelength of $1.5406167 \AA$ was used to probe the samples on a scanning rate of $0.02 \%$ in the $2 \theta$ range from 10 to 80 . Scanning electron microscopy (SEM) and high-resolution transmission electron microscopy (HRTEM) were used for the morphological study of the samples. Energy dispersive X-ray spectroscopy (EDX) and X-ray photoelectron spectroscopy (XPS) were used to evaluate the elemental composition and purity of the samples. Ultraviolet visible spectroscopy (UV-vis) and photoluminescence (PL) spectroscopy were used to study the optical properties of the prepared samples.

\subsection{Photocatalytic Property}

The photocatalytic degradation activity of the prepared samples was investigated against methylene blue. For this, a homogeneous solution was obtained by mixing $2 \mathrm{mg}$ of methylene blue in $500 \mathrm{~mL}$ of distilled water. Six beakers, each with $50 \mathrm{~mL}$ of this solution were prepared and added with $20 \mathrm{mg}$ of $\mathrm{CuO}$ in each beaker. The five beakers out of these six were added $1-5 \mathrm{wt} . \%$ of Mo. The obtained final solutions were stirred for $30 \mathrm{~min}$ in a dark environment such as to attain adsorption-desorption equilibrium. Then, the prepared final solution was kept in a photocatalytic reactor and $3 \mathrm{~mL}$ from each sample's solutions was taken out after $0,30,60,90$, and $120 \mathrm{~min}$, which were also centrifuged to eliminate the photocatalyst. The degraded amount of methylene blue was then measured from each sample by using a spectrometer. Percentage decrease in the absorption for dye at the surface of the catalyst is a measure of degradation efficiency. The maximum efficiency 
was obtained at a wavelength of $992 \mathrm{~nm}$, due to introduction of catalysts, by the following formula.

$$
\% \text { Degradation }=\left(\left(C_{0}-C_{t}\right) / C_{0}\right) \times 100
$$

Here, $C_{0}$ and $C_{t}$ are the initial and after time " $t$ " concentrations of the dye [32].

\section{Conclusions}

In summary, the optical and photocatalytic activity of $\mathrm{CuO}$ was tuned by fabricating Mo-doped $\mathrm{CuO}$ nanomaterials. The structural, morphological, and optical properties were investigated using different techniques. The results showed that all these properties were improved after doping $\mathrm{CuO}$ with molybdenum. Furthermore, the photocatalytic activity results for the degradation of $\mathrm{MB}$ dye showed that the Mo-doped $\mathrm{CuO}$ nanomaterials were effective photocatalysts. Among all samples, $\mathrm{MoCu}-4$ has demonstrated an excellent photocatalytic performance in the degradation of MB dye. Hence, this sample can be ideally employed for the purification of water by degrading the methylene blue present in it.

Author Contributions: Conceptualization, W.S. and M.M.; methodology, M.M. and A.R.; formal analysis, X.W.; investigation, J.C.; data curation, J.C.; writing—original draft preparation, M.M. and A.R.; writing—review and editing, K.N.R.; visualization, X.W.; supervision, W.S. and K.N.R.; project administration, W.S.; funding acquisition, W.S. All authors have read and agreed to the published version of the manuscript.

Funding: This research was supported in part by the funding (Nos. T31200992001 and T3120097921) for the Bagui Talent of Guangxi Province, Talent Model Base (No. AD19110157), Disinfection Robot Based on High Power AlGaN-based UVLEDs (No. BB31200014), the Guangxi Science and Technology Program (No. AD19245132), the Guangxi Science and Technology Base and Talent Special Project (No. AD2023893). Guangxi Science and Technology Base and Talented Special Project (No. AD20238088).

Acknowledgments: The authors acknowledge the support for Guangxi Science and Technology department and the Guangxi government for support to accomplish this project.

Conflicts of Interest: The authors declare no conflict of interest.

\section{References}

1. Xing, M.; Zhang, J.; Chen, F.; Tian, B. An economic method to prepare vacuum activated photocatalysts with high photo-activities and photosensitivities. Chem. Commun. 2011, 47, 4947-4949. [CrossRef]

2. Gebreslassie, T.W.; Pattabi, M.; Pattabi, R.M. Review on the photocatalytic degradation of dyes and antibacterial activities of pure and doped-ZnO. Int. J. Sci. Res. 2015, 4, 2252-2264.

3. Bhatnagar, A.; Sillanpää, M. Utilization of agro-industrial and municipal waste materials as potential adsorbents for water treatment-A review. Chem. Eng. J. 2010, 157, 277-296. [CrossRef]

4. Al-Shammiri, M.; Al-Saffar, A.; Bohamad, S.; Ahmed, M. Waste water quality and reuse in irrigation in Kuwait using microfiltration technology in treatment. Desalination 2005, 185, 213-225. [CrossRef]

5. Baur, E.; Perret, A. Über die einwirkung von licht auf gelöste silbersalze in gegenwart von zinkoxyd. Helvet. Chim. Acta 1924, 7, 910-915. [CrossRef]

6. Hanaor, D.A.; Sorrell, C.C. Sand Supported Mixed-P hase $\mathrm{TiO}_{2}$ Photocatalysts for Water Decontamination Applications. Adv. Eng. Mater. 2014, 16, 248-254. [CrossRef]

7. Peternel, I.T.; Koprivanac, N.; Božić, A.M.L.; Kušić, H.M. Comparative study of UV/ $\mathrm{TiO}_{2}, \mathrm{UV} / \mathrm{ZnO}$ and photo-Fenton processes for the organic reactive dye degradation in aqueous solution. J. Hazard. Mater. 2007, 148, 477-484. [CrossRef]

8. Wang, X.; Zhang, G.; Yang, L.; Sharman, E.; Jiang, J. Material descriptors for photocatalyst/catalyst design. Wiley Interdisciplinary Rev. Comput. Mol. Sci. 2018, 8, e1369. [CrossRef]

9. Kadi, M.W.; Mohamed, R.M.; Ismail, A.A.; Bahnemann, D.W. Decoration of mesoporous graphite-like $\mathrm{C}_{3} \mathrm{~N}_{4}$ nanosheets by NiS nanoparticle-driven visible light for hydrogen evolution. Appl. Nanosci. 2018, 8, 1587-1596. [CrossRef]

10. Khalid, N.; Ahmed, E.; Ikram, M.; Ahmad, M.; Phoenix, D.; Elhissi, A.; Ahmed, W.; Jackson, M. Effects of calcination on structural, photocatalytic properties of $\mathrm{TiO}_{2}$ nanopowders via TiCl 4 hydrolysis. J. Mater. Eng. Perform. 2013, 22, 371-375. [CrossRef]

11. Ahmad, I.; Akhtar, M.S.; Ahmed, E.; Ahmad, M.; Keller, V.; Khan, W.Q.; Khalid, N. Rare earth co-doped ZnO photocatalysts: Solution combustion synthesis and environmental applications. Separat. Purificat. Technol. 2020, 237, 116328. [CrossRef]

12. Khalid, N.; Bilal, M.; Tahir, M.; Shakil, M.; Iqbal, T.; Rafique, M.; Yousaf, N.; Gillani, S. Interfacial coupling effect of Ag $2 \mathrm{O}$ nanorods over $\mathrm{MoS}_{2}$ microflowers for improved photocatalytic activity. Ceram. Int. 2020, 46, 6856-6859. [CrossRef]

13. Chen, J.; Mao, S.; Xu, Z.; Ding, W. Various antibacterial mechanisms of biosynthesized copper oxide nanoparticles against soilborne Ralstonia solanacearum. RSC Adv. 2019, 9, 3788-3799. [CrossRef] 
14. Iqbal, M.; Thebo, A.A.; Shah, A.H.; Iqbal, A.; Thebo, K.H.; Phulpoto, S.; Mohsin, M.A. Influence of Mn-doping on the photocatalytic and solar cell efficiency of $\mathrm{CuO}$ nanowires. Inorg. Chem. Commun. 2017, 76, 71-76. [CrossRef]

15. Dhineshbabu, N.; Rajendran, V.; Nithyavathy, N.; Vetumperumal, R. Study of structural and optical properties of cupric oxide nanoparticles. Appl. Nanosci. 2016, 6, 933-939. [CrossRef]

16. Sankaran, A.; Kumaraguru, K.; Balraj, B. Structural and optical behavior of $\mathrm{CuO} / \mathrm{Ag}$ and $\mathrm{CuO} / \mathrm{Ag} / \mathrm{Au}$ nanocatalysts synthesized via a novel two step synthesis approach for enhancement of catalytic activity. J. Inorg. Organomet. Polym. Mater. 2021, 31, 151-161. [CrossRef]

17. Kim, K.; Choi, P.G.; Itoh, T.; Masuda, Y. Effect of Coordinatively Unsaturated Sites in MOF-Derived Highly Porous CuO for Catalyst-Free ppb-Level Gas Sensors. Adv. Mater. Interfaces 2021, 2021, 2100283. [CrossRef]

18. Basyooni, M.A.; Shaban, M.; El Sayed, A.M. Enhanced gas sensing properties of spin-coated Na-doped ZnO nanostructured films. Sci. Rep. 2017, 7, 41716. [CrossRef] [PubMed]

19. Liu, K.; Yuan, S.; Duan, H.; Yin, S.; Tian, Z.; Zheng, X.; Huo, S.; Wang, C. A comparative study on the magnetic properties of Fe-doped CuO nanopowders prepared by sol-gel and co-precipitation method. Mater. Lett. 2010, 64, 192-194. [CrossRef]

20. Ekthammathat, N.; Phuruangrat, A.; Thongtem, T.; Thongtem, S. Synthesis and characterization of Ce-doped CuO nanostructures and their photocatalytic activities. Mater. Lett. 2016, 167, 266-269. [CrossRef]

21. Muthuvel, A.; Jothibas, M.; Manoharan, C. Synthesis of copper oxide nanoparticles by chemical and biogenic methods: Photocatalytic degradation and in vitro antioxidant activity. Nanotechnol. Environ. Eng. 2020, 5, 14. [CrossRef]

22. Al-Amri, S.; Shahnawaze Ansari, M.; Rafique, S.; Aldhahri, M.; Rahimuddin, S.; Azam, A.; Memic, A. Ni doped CuO nanoparticles: Structural and optical characterizations. Curr. Nanosci. 2015, 11, 191-197. [CrossRef]

23. Tenkyong, T.; Bachan, N.; Raja, J.; Kumar, P.N.; Shyla, J.M. Investigation of sol-gel processed CuO/SiO 2 nanocomposite as a potential photoanode material. Mater. Sci. Poland 2015, 33, 826-834. [CrossRef]

24. Basu, M.; Sinha, A.K.; Pradhan, M.; Sarkar, S.; Pal, A.; Pal, T. Monoclinic CuO nanoflowers on resin support: Recyclable catalyst to obtain perylene compound. Chem. Commun. 2010, 46, 8785-8787. [CrossRef] [PubMed]

25. Vernickaite, E.; Lelis, M.; Tsyntsaru, N.; Pakštas, V.; Cesiulis, H. XPS studies on the Mo oxide-based coatings electrodeposited from highly saturated acetate bath. Chemija 2020, 31. [CrossRef]

26. Phang, Y.-K.; Aminuzzaman, M.; Akhtaruzzaman, M.; Muhammad, G.; Ogawa, S.; Watanabe, A.; Tey, L.-H. Green Synthesis and Characterization of CuO Nanoparticles Derived from Papaya Peel Extract for the Photocatalytic Degradation of Palm Oil Mill Effluent (POME). Sustainability 2021, 13, 796. [CrossRef]

27. Khalid, N.; Israr, Z.; Tahir, M.; Iqbal, T. Highly efficient $\mathrm{Bi}_{2} \mathrm{O}_{3} / \mathrm{MoS}_{2}$ pn heterojunction photocatalyst for $\mathrm{H}_{2}$ evolution from water splitting. Int. J. Hydrog. Energy 2020, 45, 8479-8489. [CrossRef]

28. Kumar, P.; Sharma, A.; Dahiya, S. XRD and Band Gap Study of SrDopedCuONano Particles by Sol Gel Method. 2017. Available online: https://d1wqtxts1xzle7.cloudfront.net/54440666/2816.pdf?1505475901=\&response-content-disposition= inline\%3B+filename\%3DXRD_and_Band_Gap_Study_of_SrDopedCuONano.pdf\&Expires=1632918952\&Signature=P0kITPub \{\}-WWO06tzun1eef8MEkHzwSAMbVnONuVegRpFHR8Rrt \{\}BwPOIze3cqeRndllwKdi0IYfWOMGZGc3PJad7N0k \{\}W0 YYsg9a4xxiX8BsJUY3x5D7X0m57RFV1xUiZt48Qu6hXnY6C31Nphgd3xy9wsn5TgobJCWJOebFYj7ISG5hr48wwGD15ybj3IEYPdk-UQ1ulbeQBTqJUQEyHT11ay2xVRV3x \{\}gkGRvfE4DY2t4wK5RtXkS8JZCeAEtGosgj3fSs3injyjWiUlsh-SWEA7vADOsRzcijUNRSUyO7vNYDgtlUVZ \{\}jGTBeW3koFFOm6VcQwyT21VeLdAQ_\&Key-Pair-Id=APKAJLOHF5GGSLRBV4ZA (accessed on 29 September 2021).

29. Karthik, P.; Kumar, T.N.; Neppolian, B. Redox couple mediated charge carrier separation in g- $\mathrm{C}_{3} \mathrm{~N}_{4} / \mathrm{CuO}$ photocatalyst for enhanced photocatalytic $\mathrm{H}_{2}$ production. Int. J. Hydrog. Energy 2020, 45, 7541-7551. [CrossRef]

30. Nadeem Riaz, K.; Yousaf, N.; Bilal Tahir, M.; Israr, Z.; Iqbal, T. Facile hydrothermal synthesis of 3D flower-like La-MoS2 nanostructure for photocatalytic hydrogen energy production. Int. J. Energy Res. 2019, 43, 491-499. [CrossRef]

31. Salari, H.; Sadeghinia, M. MOF-templated synthesis of nano $\mathrm{Ag}_{2} \mathrm{O} / \mathrm{ZnO} / \mathrm{CuO}$ heterostructure for photocatalysis. J. Photochem. Photobiol. A Chem. 2019, 376, 279-287. [CrossRef]

32. Kadhim, R.G.; Kzar, K. Structural and optical properties of CuO doped (Li) thin films prepared by sol-gel technique. World Sci. News 2016, 56, 56-66. 